\title{
Proses Transformasi Pengetahuan Budaya Songket pada Masyarakat Pandai Sikek
}

\section{Knowledge Transformation Process in Weaving Culture in Pandai Sikek Society}

\author{
Elfitri Kurnia Erza ${ }^{1}$, Pawit M. Yusup ${ }^{2}$, Wina Erwina ${ }^{3}$ \\ ${ }^{I}$ Program Studi Ilmu Perpustakaan Fakultas Teknologi Informasi Universitas YARSI \\ ${ }^{2,3}$ Program Studi Ilmu Informasi dan Perpustakaan Fakultas Ilmu Komunikasi Universitas \\ Padjadjaran \\ E-mail: elfitri.kurnia@yarsi.ac.id
}

KEYWORDS knowledge transformation, indigenous knowldge, weaving culture

ABSTRACT Information development has prompted a transition within society, which has changed from local society to information society. The transition appears accordingly in the process of knowledge sharing of "Songket" waving technic in Pandai Sikek. This social phenomenon necessarily affects local knowledge of the community and initiates some knowledge transformation. The aim of this paper is to see how exactly the transformation of the local knowledge of "Songket" waving technic as a part of society's culture arise. The paper employs qualitative methods combined with ethnographical approach. Data are collected through observation, in depth interview, and documentation studies. Conducted research shows that the cultural knowledge regarding Songket has altered from a belief system to a social factor of the society involved.

\section{PENDAHULUAN}

Pandai Sikek merupakan suatu daerah pedesaan yang memiliki hasil songket yang terkenal di dalam dan luar negeri. Pandai Sikek adalah salah satu dari dua daerah penghasil songket di Sumatera Barat selain Silungkang. Songket merupakan hasil tenun yang menggunakan benang emas. Pembuatan songket pada dasarnya di setiap daerah Sumatera Barat menggunakan bahan dan alat yang sama. Namun, perbedaannya terlihat dari siapa yang boleh mendapatkan pengetahuan tentang songket ini. pada daerah Silungkang, pembuat songket bisa dari kalangan mana saja, sehingga disini terlihat pembuat songket bekerja seperti buruh tenun umumnya. Sedangkan hal berbeda terlihat dari pola penurunan pengetahuan yang dilakukan oleh masyarakat Pandai Sikek.
Dimana pada daerah Pandai Sikek dikenal dengan istilah sumpah sati nek moyang yang artinya terdapat sumpah nenek moyang dalam mengatur pola pewarisan pengetahuan mengenai songket. Masyarakat Pandai Sikek merupakan masyarakat lokal, dimana menurut Arnold (dalam Masango 2010) indigenous people atau masyarakat lokal merupakan sekumpulan orang yang berada pada wilayah serta dianggap sebagai pribumi dikarenakan keturunan mereka dari wilayah yang dihuni secara geografis atau penaklukan daerah pada masa penjajahan.

Pada tahun 1913 terdapat dokumen yang berisi mengenai filosofis dari motif yang dihasilkan masyarakat Pandai Sikek. Dokumen ini berisikan bagaimana kehidupan masyarakat Pandai Sikek yang dituangkan dalam hasil tenunan mereka. Berdasarkan hasil dokumentasi diketahui bahwa kepercayaan yang mereka miliki 
sangat bersifat sakral. Walaupun pada masa itu songket juga menjadi hasil ekonomi masyarakat namun pengguna songket hanya orang-orang tertentu saja. Sehingga mereka tetap tidak mengajarkan pada siapapun mengenai pengetahuan ini. Pada saat penjajahan Jepang terjadi gejolak yang mengakibatkan terhentinya aktivitas tenun di Pandai Sikek. Namun, mereka tetap menyimpan hanya untuk diri mereka sendiri.

Pada zaman dahulu sebelum perkembangan teknologi informasi sangat luas, sumber informasi utama adalah Datuak yang merupakan pemimpin adat dimana Datuak berfungsi dalam mengambil kebijakan, memastikan nilai dan norma berjalan sesuai dengan fungsinya serta berbagai aturan lain yang dijadikan pedoman bagi masyarakat Pandai Sikek dalam mengelola pengetahuan lokal yang mereka miliki. Datuak berfungsi sebagai penjaga agar dalam nilai dan norma budaya pada masyarakat tetap berjalan dengan lancar dan sesuai dengan aturan.

Pada saat sekarang, dimulai tahun 2007 setelah terjadi gempa yang cukup berdampak pada masyarakat, Cita Tenun Indonesia hadir yang pada saat itu diketua oleh Ibu Mufidah Kalla. Beliau melakukan pemberdayaan pada daerah penghasil tenun yang ada di Indonesia dan menyarankan untuk dibentuk pusat kegiatan tenun masyarakat. Sehingga dibangun Pusat Inovasi Tenun Songket Pandai Sikek yang pada awalnya hanya untuk mengembangkan pengetahuan yang sudah ada. Sampai pada saat sekarang Pusat Inovasi Tenun Songket Pandai Sikek selain untuk mengembangkan inovasi juga menyusun dokumentasi pengetahuan mengenai motif, teknik pembuatan dan teknologi. Hal ini mengakibatkan keterbukaan mereka untuk memberitahukan orang di luar Pandai Sikek mengenai inovasi dan teknologi yang mereka lakukan dalam menghasilkan songket.
Untuk menanggulangi kepunahan yang mungkin terjadi dimasa yang akan datang pada tahun 2009 dilakukan pendaftaran Hak Kekayaan Intelektual untuk beberapa motif dan teknologi pengembangan masyarakat Pandai Sikek. Perpindahan dari bentuk tacit ke bentuk tertulis seperti yang dilakukan masyarakat Pandai Sikek mengindikasikan terjadinya transformasi pengetahuan. Dimana terjadi perubahan bentuk yang sangat sakral dan terdapat banyak unsur tradisional menjadi pengetahuan yang bersifat dinamis dan terbuka untuk diketahui oleh orang banyak.

Adanya keterbukaan pemikiran untuk mau mengembangkan pengetahuan yang lebih luas lagi menandakan masyarakat Pandai Sikek beralih dari masyarakat lokal yang berbasis kepercayaan menjadi masyarakat informasi yang berbasis inovasi. Pijbers (2010) juga mengemukakan bahwa informasi dapat menggantikan sumber daya yang dapat menyebar dan mengalami perubahan. Informasi adalah manusia, informasi ada karena persepsi manusia. Nilai informasi diberikan oleh manusia sebagai pengguna informasi serta bagaimana informasi yang sudah ada kemudian digunakan sebagai pengetahuan. Selain itu terjadinya transformasi pengetahuan apabila kebutuhan semakin mendesak dan mengalami ancaman maka akan terjadi krisi kebudayaan dan krisis nilai sehingga membutuhkan perubahan (Sutrisno 2008, 20).

Sehingga diperlukan pemaparan bagaimana proses peralihan pengetahuan masyarakat yang dinamakan dengan transformasi pengetahuan. Proses transformasi dapat dilihat dengan membandingkan masyarakat pada saat sebelum terjadinya transformasi dan setelah terjadinya transformasi. Sejalan dengan itu Nakata dan Langton (2005, dalam Anyira dkk 2010) menyatakan bahwa pengetahuan lokal yang diciptakan masyarakat lokal dari waktu ke waktu mencakup teknologi, pengetahuan, 
keterampilan, praktik dan keyakinan yang membuat keadaan masyarakat menjadi stabil. Oleh karena itu pada artikel ini akan dibahas mengenai proses transformasi pengetahuan mengenai budaya songket pada masyarakat Pandai Sikek.

\section{METODOLOGI}

Penelitian ini menggunakan metode kualitatif dengan menekankan pada pandangan subjektif penulis dalam memahami makna individu dari subjek yang diteliti. Penulis mengulas realitas di lapangan dari segi komunikasi masyarakat dan mengaitkannya dengan teori komunikasi. Menurut Denzin dan Lincoln (2005) penelitian kualitatif merupakan penelitian yang bersifat interpretif yang menggunakan metode dalam upaya membahas masalah penelitian. Penelitian kualitatif digunakan untuk melihat kehidupan serta perilaku sosial sesuai pernyataan Flick (2009) bahwa penelitian kualitatif sangat relevan dalam pengungkapan hubungan sosial serta faktafakta keberagaman kehidupan sosial.

Pada penelitian ini metode kualitatif dilakukan dengan pendekatan etnografi. Menurut Creswell (2006) "Ethnography is qualitative design in which the researcher describe and interprets the shared and learned pattern of values, behavior, belief and language of a culture-sharing group" (Creswell 2006, 68). Pendekatan ethnografi digunakan untuk melihat suatu budaya secara utuh melewati semua aspek budaya yang bersifat terlihat berupa dokumen dan artefak budaya serta tidak terlihat seperti pengalaman, norma dan sistem nilai kelompok. Pengumpulan data dilakukan dengan observasi, wawancara mendalam dan studi dokumentasi. Kemudian data diolah dengan melakukan triangulasi data dokumentasi dan sumber.

Populasi dalam penelitian ini adalah masyarakat Pandai Sikek yang terjun langsung dalam bidang inovasi dan pengembangan pengetahuan songket.
Pengambilan sampel dilakukan dengan teknik snowball sampling dimana dipilih satu orang pertama yang menjadi informan kunci. Jumlah informan kunci dalam penelitian ini sebanyak 6 orang yang merupakan rekomendasi dari informan kunci sebelumnya. Pengumpulan data dinyatakan cukup ketika informasi yang di dapatkan peneliti sudah berulang.

ISI

Terjadinya transformasi pengetahuan merupakan tuntutan dalam mengikuti perkembangan industri yang berbasis masyarakat. Masyarakat Pandai Sikek sebagai masyarakat lokal yang memiliki budaya. Budaya songket yang menjadi pegangan kehidupan sosial dan ekonomi masyarakat. Secara sosial masyarakat memberi makna pada songket yang mereka hasilkan adalah identitas. Hal ini yang kemudian dikenal dengan anak gadih yang ndak bisa batanun bukan urang Pandai Sikek (anak gadis yang tidak bisa menenun bukan orang Pandai Sikek). Sedangkan secara ekonomi, songket menjadi profesi yang masyarakat Pandai Sikek dapat menjadi penopang kehidupan. Adanya peran sosial dan ekonomi yang terkandung dalam satu budaya songket di masyarakat lokal sesuai dengan pemaparan yang dikemukakan oleh Mulyana (2010) bahwa budaya adalah pola yang menyeluruh. Dimana keberadaan budaya songket bagi masyarakat Pandai Sikek menentukan bagaimana cara dan perilaku dalam berkomunikasi. Hal senada juga diungkapkan oleh Barnhardt dan Kawagley (2005) (dalam Teffo 2011) bahwa masyarakat lokal mempertahankan pandangan mereka yang berkaitan dengan sistem pengetahuan yang sudah ada dalam bentuk nilai, keyakinan, dan cara berhubungan antar sesama serta antargenerasi. Adanya pengetahuan lokal menurut World Bank menjadi salah satu strategi pemecahan masalah sosial dan ekonomi masyarakat. Sehingga bagi masyarakat Pandai Sikek budaya tenun 
songket merupakan identitas diri sebagai masyarakat lokal yang memiliki aturan tersendiri yang dipercaya turun temurun (Gambar 1.)

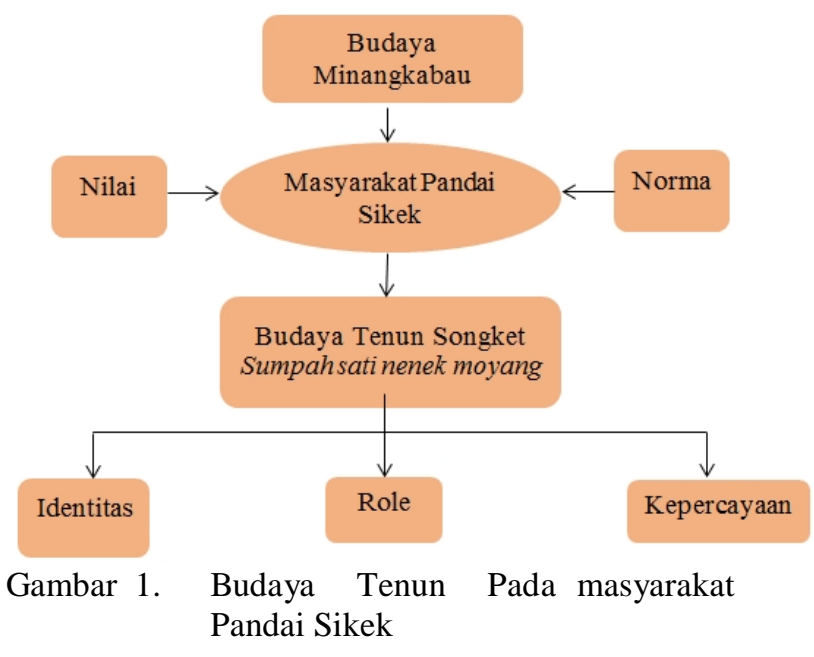

Dilihat dari budaya songket yang dahulunya hanya dilakukan oleh perempuan. Pengetahuan lokal mengenai budaya songket ini mengalami pergeseran dimana dahulunya perempuan menjadi pemeran utama sebagai pemilik dan ujung tombak pengetahuan budaya songket. Saat ini kaum laki-laki menjadi penyokong terjadinya pengembangan dan pelestarian pengetahuan budaya songket. Perubahan ini mengindikasi bahwa adanya pengetahuan lokal yang ada di Pandai Sikek sudah bersifat dinamis. Dimana pengetahuan yang ditransmisikan dengan cara oral tradition mengalami keberlanjutan seiring dengan berjalannya waktu. Nakata (2005) menyatakan bahwa indigenous knowledge is always in a sense contemporary, sifat kontemporer yang ada pada pengetahuan lokal diakibatkan adanya sistem pengetahuan yang mulai terbuka dan didukung oleh adanya teknologi. Bagi kaum laki-laki sebagai pemeran aktif baru dalam budaya songket di Pandai Sikek budaya songket tidak hanya perlu pengembangan untuk meningkatkan nilai jual, tetapi juga menjadi tantangan untuk mempertahakan nilai budaya melalui tindakan pelestarian dan pendokumentasian. Perlunya pelestarian dan pendokumentasian ini untuk memperjelas makna bahwa songket Pandai Sikek merupakan identitas bagi masyarakat Pandai Sikek. Kesadaran ini ada karena adanya informasi dari berbagai daerah penghasil songket lainnya yang mengalami kemajuan dan kemuduran, sehingga diperlukan penegasan makna untuk anak nagari Pandai Sikek. Makna songket bagi masyarakat Pandai Sikek saat ini merupakan hasil dari interaksi individu dalam masyarakat, hal ini sesuai dengan pemaparan teori intraksi simbolik bahwa makna merupakan hasil dari interaksi manusia dikemukakan oleh George Herbert Mead pada awal abad 20 an (Effendi 2003). Pada draft WIPO (2014) juga dijelaskan bahwa pengetahuan lokal tidak langsung ada dalam masyarakat melainkan melalui berbagai proses penurunan, pengamatan serta pengungkapan dari pengetahuan berdasarkan kepercayaan. Proses terjadinya transformasi pengetahuan didorong oleh keadaan dalam diri masyarakat dan lingkungan di luarnya. Adapun faktor pendorong yang berasal dari dalam masyarakat dapat dilihat dari kepercayaan masyarakat, produksi lokal dan ketakutan akan kepunahan. Kepercayaan masyarakat yang menganggap bahwa pengetahuan mengetahui budaya songket merupakan hal yang sangat sakral, hal ini dapat dilihat kepercayaan bahwa bagi siapa saja yang berani mengajarkan pengetahuan yang mereka miliki akan mendapatkan kemalangan. Kemudian, adanya produksi lokal yang menjadi nilai budaya yang sudah melekat dalam diri masyarakat. Dimana songket menjadi barang seperti perhiasan atau tanda yang diberikan oleh mertua kepada menantu, acara pernikahan, pakaian kebesaran Bundo Kanduang dan Panghulu serta hantaran yang diberikan bako kepada anak pisang yang menikah. Faktor pendorong lainnya yang bersal dari dalam diri masyarakat adalah ketakutan akan kepunahan yang jika diabaikan akan 
mengakibatkan ketidakberlanjutan budaya tenun seperti beberapa daerah yang sudah mengalami kepunahan.

Adanya faktor pendorong dalam diri masyarakat ini menurut teori Parson merupakan hasil dari penyesuaian diri masyarakat dengan lingkungan sekitar mereka. Banyaknya informasi yang terbentuk dari hasil interaksi dalam diri masyarakat membuat proses perubahan sosial masyarakat dapat terjadi. Informasi yang bernada ancaman kepunahan dan pengambilan pengetahuan oleh orang luar menjadi faktor pendorong yang sangat melekat dalam diri masyarakat.

Adanya proses terjadinya transformasi pengetahuan lokal pada masyarakat terjadi karena adanya dorongan dari luar diri masyarakat. Teknologi yang sangat menonjol terlihat pada modifikasi alat tenun, modifikasi teknik pembuatan dan motif songket. Hal ini yang diungkapkan oleh Nakata (2005) bahwa pengetahuan yang selalu berubah terlihat dari hasil pemikiran dalam bentuk inovasi dan teknologi. Teknologi yang berkembang di luar Pandai Sikek menjadi referensi untuk dijadikan pengetahuan baru dan disesuaikan dengan pengetahuan yang ada sekarang tanpa harus mengubah nilai dari pengetahuan lokal yang sebenarnya. Keberadaan teknologi dan inovasi juga merupakan hal yang sejalan. Adanya teknologi dan inovasi merupakan hasil pemikiran dan penciptaan pengetahuan baru. Menurut WIPO (2014) pada draft traditional knowledge, pengetahuan lokal mengacu pada instrument pengetahuan yang meliputi keterampilan, inovasi, praktik serta proses pembelajara yang dilakukan oleh masyarakat.

Kebutuhan pasar yang meningkat menjadi salah satu krisis yang dialami masyarakat Pandai Sikek. Hal ini menjadi tantangan di tengah keadaan masyarakat yang menuntut generasi memiliki pendidikan yang tinggi mengakibatkan jumlah penenun berkurang sehingga jumlah songket yang dihasilkan pun berkurang. Hal ini yang mendorong penciptaan teknologi dan inovasi yang dapat memangkas waktu pembuatan dari satu bulan menjadi dua minggu saja namun secara kualitas yang dihasilkan sama. Adanya desakan ini juga dinyatakan oleh Sutrisno (2008) bahwa semakin mendesak kebutuhan masyarakat maka akan terjadi krisi kebudayaan dan krisis nilai yang menuntut untuk dilakukan perubahan (Gambar 2.).

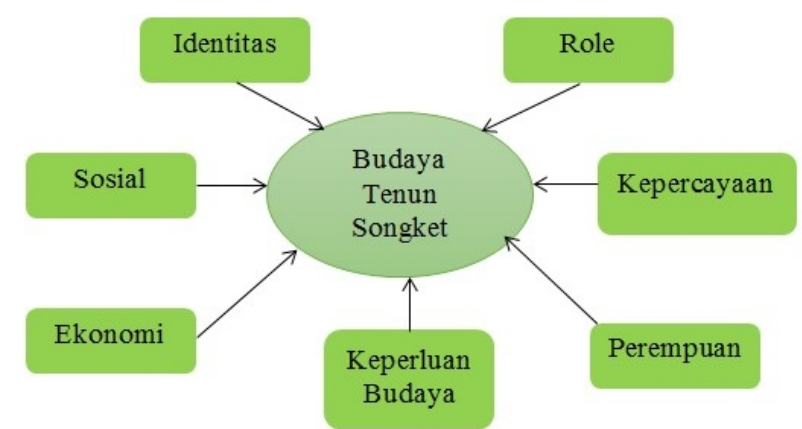

Gambar 2. Budaya tenun songket bagi masyarakat Pandai Sikek sebelum terjadinya transfor- masi pengetahuan

Matowanyika (dalam Grenier 1998) menyatakan bahwa transformasi pengetahuan lokal terjadi karena adanya ledakan jumlah penduduk. Hal ini tidak 


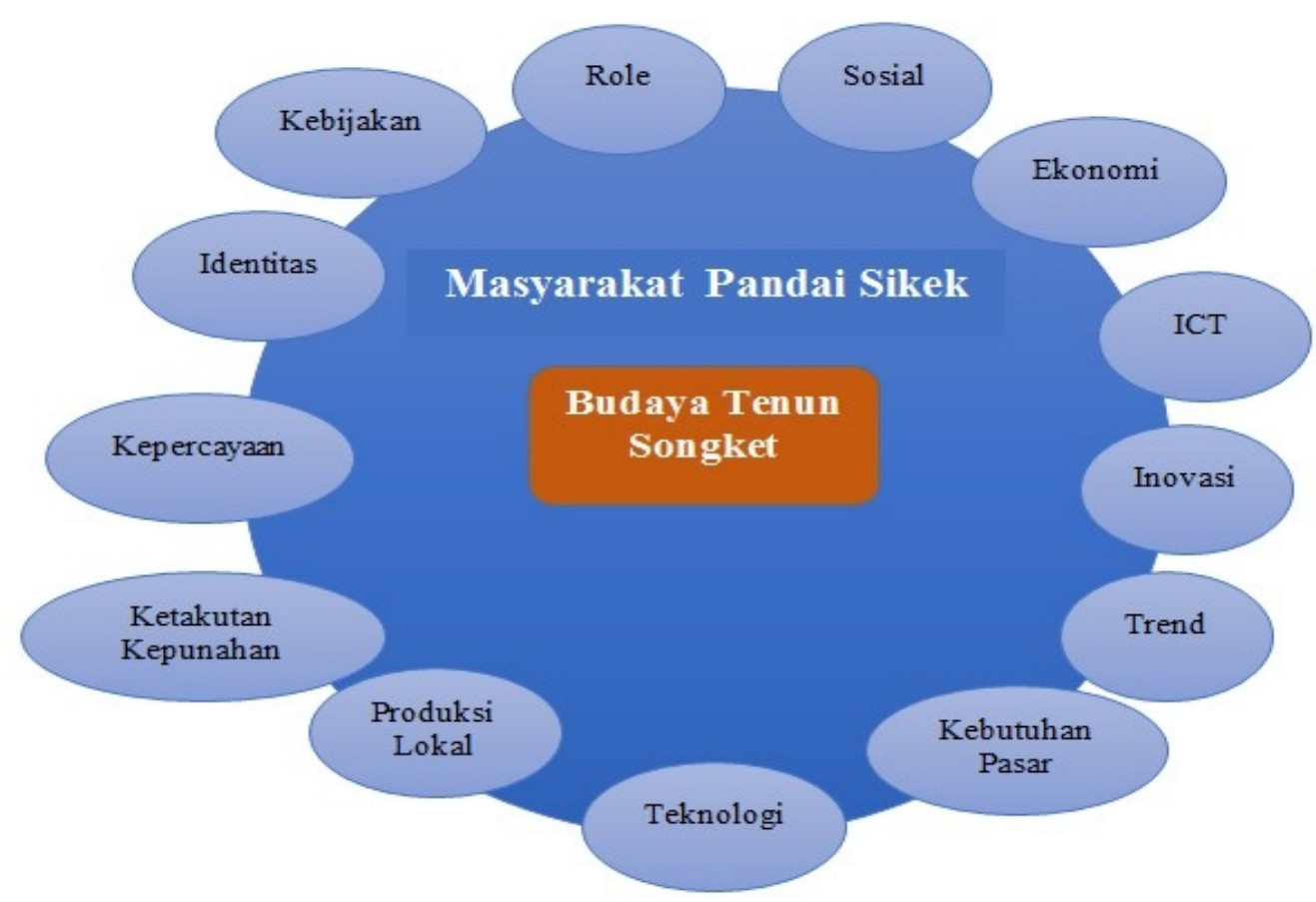

Gambar 3. Budaya tenun songket bagi masyarakat Pandai Sikek pada proses terjadinya transformasi pengetahuan

terjadi pada masyarakat lokal di Pandai Sikek. Walaupun jumlah masyarakat secara kuantitas meningkat, namun jumlah penenun dapat dikatakan menurun. Hal ini yang menjadi ancaman bagi masyarakat sehingga diperlukan pengembangan dan penciptaan pengetahuan baru dalam bentuk teknologi dan inovasi. Desakan kebutuhan pasar dengan jumlah penenun yang berkurang setiap tahunnya mendorong terjadinya proses transformasi pengetahuan.

\section{PENUTUP}

Terjadinya proses transformasi pengetahuan masyarakat Pandai Sikek yang dilihat dari aspek masyarakat terdiri dari tiga aspek. Pertama, secara sosial dahulunya masyarakat menjadikan perempuan sebagai pemilik utama pengetahuan, sedangkan pada saat sekarang laki-laki hadir untuk melakukan pendokumentasian dan pelestarian pengetahuan. Kedua, masyarakat memiliki faktor internal yang mendorong terjadinya transformasi pengetahuan yaitu kepercayaan masyarakat, produksi lokal dan ketakutan mereka akan kepunahan. Terakhir, faktor eksternal yang mendorong terjadinya transformasi pengetahuan pada masyarakat Pandai Sikek dilihat dari adanya teknologi, kebutuhan pasar dan inovasi. Masyarakat Pandai Sikek secara sadar mengalami berbagai desakan untuk menjadikan pengetahuan lokal yang dahulunya statis menjadi dinamis dilihat dari perilaku masyarakatnya.

\section{DAFTAR PUSTAKA}

Anyira, I, et all, 2010. The Role Of Libraries In The Preservation And Accessibility Of Indigenous Knowledge In The Niger Delta Region Of Nigeria. Library Philosophy And Practice 2010

Creswell J W, 2006. Qualitative Inquiry \& Research Design: Choosing Among Five Approach. London: Sage

Denzin N K \& Lincoln Y S, 2005. Qualitative Research: Third Edition. London: Sage. 
Effendy O U, 2003. Ilmu, Teori Dan Filsafat Komunikasi. Bandung: Citra Aditya Bakti

Flick U, 2009. An Introduction To Qualitative Research. London: Sage

Grenier L, 1998. Working With Indigenous Knowledge A Guide For Researchers. Ottawa: International Development Research Centre Mulyana D, 2010. Komunikasi Antarbudaya: Panduan Berkomunikasi Dengan Oran-Orang Berbeda Budaya. Bandung: Remaja Rosda Karya.

Keputusan Walinagari Pandai Sikek Nomor 7 tahun 2009 Tentang Pengangkatan Panitia Inventaris dan Pendaftaran Perlindungan Hukum Hak Kekayaan Intelektual (HAKI) Kerajinan Tradisional Tenun Antik Pandai Sikek

Masango, C A 2010, Indigenous Traditional Knowledge Protection: Prospects In South Africa's Intellectual Property Framework? Journal Library and Information Science Vol 76 No 12010.
Peraturan Nagari Pandai Sikek Nomor 3 Tahun 2006 tentang Tenun Antik Pandai Sikek

Pijpers, G, 2010. Information Overload: A System For Better Managing Everyday Data. New Jersey: John Wiley \& Sons

Sutrisno M, 2008. Filsafat Kebudayaan: Ikhtiar Sebuah Teks. Jakarta: Hujan Kabisat

Teffo, L 2011. "Epistemic Pluralism For Knowledge Transformation."

International Journal of African Renaissance Studies 6, No. 1: 24-34. Academic Search Complete, Ebscohost (Accessed May 1, 2015).

WIPO 2014, Intergovernmental Committee On Intellectual Property And Genetic Resources, Traditional Knowledge And Folklore. Geneva: WIPO 
